\title{
Panduan Navigasi Virtual Tour Pulau Kumala Kutai Kartanegara
}

\author{
Muhammad Bambang Firdaus', Andi Tejawati², Muhammad Syauqi Hafizh ${ }^{3}$, M. Khairul Anam \\ ${ }^{1,2,3}$ Universitas Mulawarman \\ ${ }^{4}$ Stmik Amik Riau \\ *bambangf@fkti.unmul.ac.id
}

\begin{abstract}
This study aims to create a virtual navigation guide video application to tour the island of Kumala, Kutai Kartanegara as a promotional media, to introduce Kumala Island and to provide guidance on the tourist route of Kumala Island. The purpose of this research can be achieved through the combination of Video Virtual Reality (VR) technology and Android mobile technology which is owned by almost every level of society so as to enable application users to view videos in $360^{\circ}$. The test results on Android devices show that the application can run smoothly and is suitable for use on versions of Android 5.1 and above with screen aspect ratios of 16: 9, 18: 9 and 19: 9. While the results of application testing based on questionnaires using simple random sampling with a total of 60 respondents distributed showed that each question from the questionnaire received an agreed and strongly agreed answer which indicated a positive response about the application that the author designed from the application user.
\end{abstract}

Keywords: virtual reality, video 360, Kumala Island

\begin{abstract}
Abstrak
Penelitian ini bertujuan untuk membuat aplikasi video panduan navigasi virtual berkeliling Pulau Kumala, Kutai Kartanegara sebagai media promosi, mengenalkan Pulau Kumala dan memberikan panduan jalur wisata Pulau Kumala. Tujuan dari penelitian ini dapat dicapai melalui perpaduan antara teknologi Video Virtual Reality (VR) dan teknologi mobile Android yang dimiliki oleh hampir semua lapisan masyarakat sehingga memungkinkan pengguna aplikasi untuk melihat video dalam $360^{\circ}$. Hasil pengujian pada perangkat Android menunjukkan bahwa aplikasi dapat berjalan dengan lancar dan cocok digunakan pada versi Android 5.1 ke atas dengan aspek rasio layar 16: 9, 18: 9 dan 19: 9. Sedangkan hasil pengujian aplikasi berdasarkan kuesioner menggunakan simple random sampling dengan jumlah 60 responden yang disebarkan menunjukkan bahwa setiap pertanyaan dari kuesioner mendapat jawaban setuju dan sangat setuju yang menandakan respon positif tentang aplikasi yang penulis rancang dari pengguna aplikasi.
\end{abstract}

Kata kunci: virtual reality, video 360, Pulau Kumala

\section{Pendahuluan}

Pariwisata merupakan sesuatu yang tidak bisa lepas dari kehidupan masyarakat Indonesia. Pariwisata memiliki manfaat di berbagai bidang di Indonesia, salah satunya Ekonomi [1]. Kutai Kartanegara memiliki tempat wisata yang biasa dikunjungi oleh pengunjung dari dalam kota hingga luar kota, antara lain Taman Budaya, Museum Mulawarman, air terjun, Pulau Kumala dan lain sebagainya. Setiap tempat wisata memiliki daya tarik tersendiri sehingga mendorong pengelola dan berbagai tempat wisata untuk mencari cara promosi agar banyak pengunjung yang tertarik untuk mengunjungi tempat wisata tersebut [2].

Pulau Kumala sendiri merupakan sebuah pulau di tengah sungai Mahakam yang memiliki berbagai tempat wisata di dalamnya, selain itu Pulau Kumala saat ini memiliki bangunan Jembatan Repo-repo yang dalam bahasa Kutai berarti "Gembok", karena di beberapa tempat di pagar jembatan a tempat khusus disediakan untuk dipasang. gembok cinta. 
Jembatan Repo-repo juga merupakan jembatan yang menghubungkan tepi mahakam Tenggarong dengan Pulau Kumala, yang memudahkan wisatawan untuk berkunjung ke Pulau Kumala, selain itu Jembatan Repo-repo di Pulau Kumala juga terdapat rumah lamin yang merupakan Rumah adat suku Dayak, dan juga terdapat Pasak Murni yang digunakan sebagai tempat peribadahan umat Hindu.

Mempromosikan Pulau Kumala yang akan dikemas dengan 360 video yang dipadukan dengan motion graphics agar wisatawan tertarik dengan Pulau Kumala. Hasil penelitian ini diharapkan dapat memberikan kontribusi untuk menjadi pemandu wisata wisata keluarga di Pulau Kumala Kabupaten Kutai Kartanegara. Hasil penelitian ini juga diharapkan dapat memberikan informasi yang lebih jelas tentang wisata keluarga Pulau Kumala, dimana wisata ini dapat memberikan sensasi dan pengalaman dalam suasana wisata Pulau Kumala.

\section{Metode Penelitian}

Metode Luther atau metode pengembangan perangkat lunak multimedia dimana metode yang digunakan adalah Multimedia Development Life Cycle [3]. Pengembangan ini terdiri dari 6 tahapan, yaitu:etoda yang dipakai dalam penelitian ini berupa langkah kerja serta rangkaian kegiatan sebagai berikut.

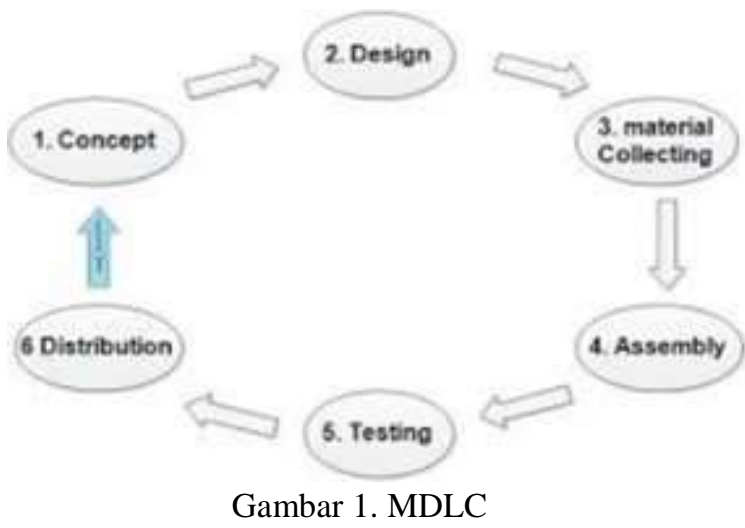

2.1 Konsep

Tahap Konsep adalah menentukan tujuan dan siapa pengguna program, jenis aplikasi, tujuan aplikasi, dan spesifikasi umum. Sasaran dasar juga ditentukan pada tahap ini, seperti ukuran aplikasi, target dan lain-lain [4].

Video promosi dan panduan yang akan dibuat dengan menggunakan motion graphic yang dikombinasikan dengan virtual reality digunakan sebagai media promosi dan panduan navigasi untuk pulau Kumala.

\subsection{Desain}

Spesifikasi aplikasi secara detail dalam sebuah desain aplikasi. Pembuatannya di sesuaikan berdasarkan penggambaran pada tahapan konsep [5].

\section{Flowchart}

Kerangka kerja yang digunakan berdasarkan diagram alir untuk menyelesaikan masalah penelitian ini adalah sebagai berikut.

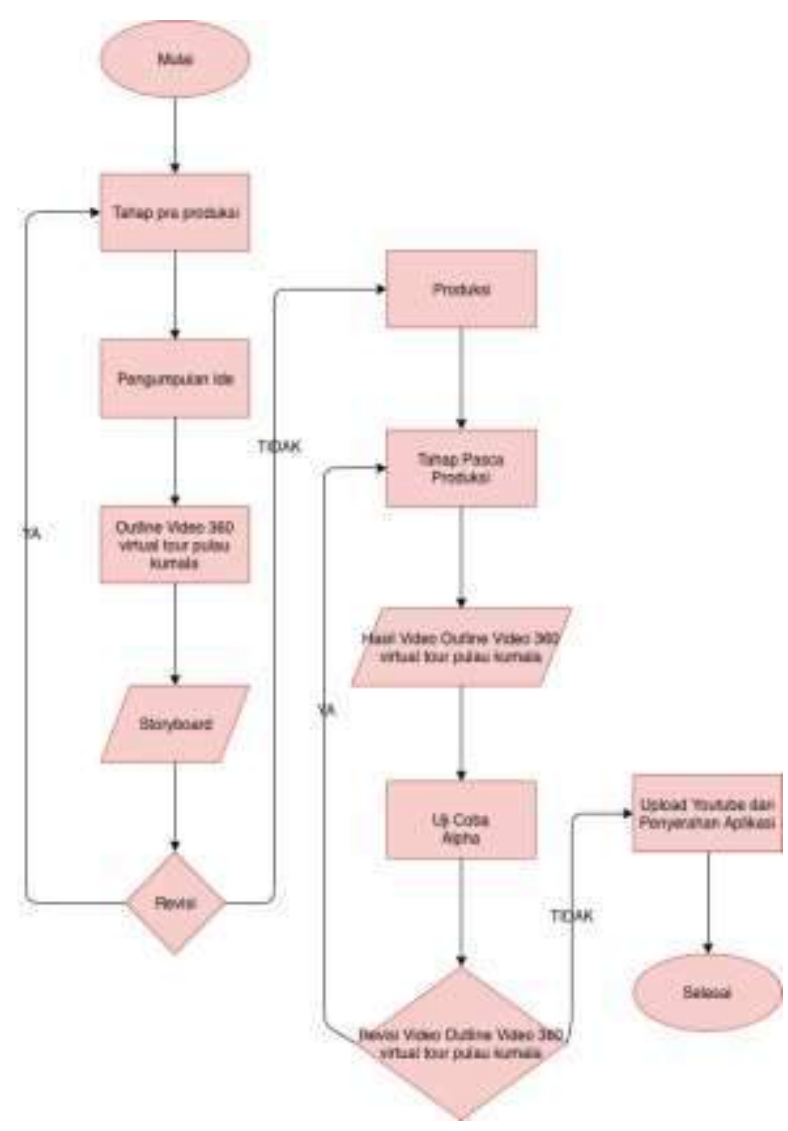

Gambar 2. Flowchart

\section{Storyboard}

Storyboard adalah sketsa gambar yang disusun menurut naskah cerita [6]. Dengan 
papan cerita, pembuat cerita dapat menyampaikan pesan dengan lebih mudah kepada orang lain [7]. Storyboard juga diperlukan sebagai ilustrasi atau panduan saat memotret [8]. Berikut ini adalah storyboard video promosi dan panduan ini:

Tabel 1. Storyboard

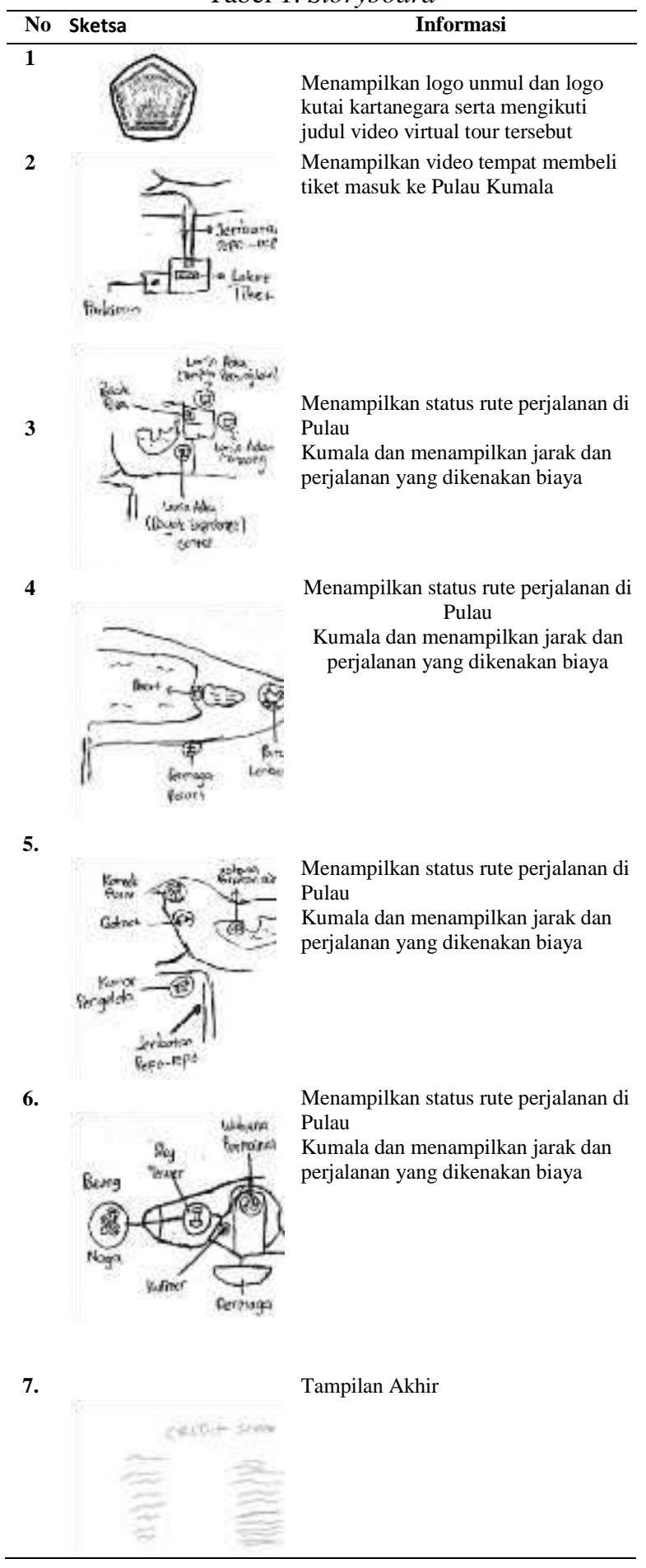

\subsection{Material Collecting}

Materi terkait video Panduan Pulau Kumala diperoleh dari wawancara dengan pengelola Pulau Kumala, membaca buku dan mencari sumber lain di internet. Sedangkan materi yang berkaitan dengan virtual reality dan motion graphics, penulis dapatkan dari buku referensi dan internet.

Assembly

Semua objek atau materi multimedia akan dibuat. Pembuatan aplikasi berdasarkan diagram alur. Semua benda atau bahan dibuat dan digabungkan menjadi satu aplikasi yang lengkap. Pada tahap ini digunakan beberapa software seperti Premiere Pro.

\subsection{Testing}

Tahapan ini disebut sebagai tahapan pengujian alpha (alpha test) dimana pengujian dilakukan oleh pabrikan atau lingkungan pabrikan itu sendiri [9]. Dalam pengujian video ini, keakuratan giroskop diuji berdasarkan gerakan . Pengujian selanjutnya adalah menguji kualitas citra yang dihasilkan, apakah pantas untuk dilihat. Tes selanjutnya menggunakan kuesioner dengan responden masyarakat.

\subsection{Distribution}

Tahap ini aplikasi yang sudah teruji dan dinyatakan baik sesuai dengan tujuan pembuatan akan didistribusikan dengan cara mengunggah akun Youtube Pribadi dan Pariwisata di Kabupaten Penajam Paser Utara.

\section{Hasil Penelitian}

\subsection{Video Editing Process}

Proses pengeditan sederhana dari video 360 yang diambil sebelumnya, dengan terlebih dahulu membuat Proyek Baru di Premiere Pro.

\subsection{Pengelompokan Data}

Setelah dilakukan pengumpulan data berupa video video 360 derajat dan ketinggian di lokasi penelitian, selanjutnya data tersebut dikumpulkan untuk dipilih untuk digunakan. Tabel ini akan menjelaskan data berupa video, nama wahana, jarak, biaya kendaraan yang akan digunakan untuk membuat video Panduan Navigasi Virtual Tour Pulau Kumala Tenggarong. 
Tabel 2. Kelompok Data

\begin{tabular}{|c|c|c|}
\hline Footage & Virtual Tour & Informasi \\
\hline \multirow[t]{4}{*}{ 1.MP4 } & Parkiran pulau & Tarif Motor \\
\hline & & Rp. 2000 \\
\hline & & Tarif mobil \\
\hline & & Rp. 5,000 \\
\hline \multirow[t]{2}{*}{ 2.MP4 } & Jembatan RepoRepo & Panjang jembatan \\
\hline & & Repo-repo adalah 230 meter \\
\hline \multirow[t]{4}{*}{ 3.MP4 } & Loket tiket & Tarif: \\
\hline & & Dewasa $\operatorname{Rp} 7.000$ \\
\hline & & Anak-anak Rp \\
\hline & & 5.000 \\
\hline 4.MP4 & Loket tiket - penyewaan & Jarak dari loket ke tempat persewaan kendaraan adalah \\
\hline & kendaraan & 300 meter \\
\hline \multirow[t]{7}{*}{ 5.MP4 } & Penyewaan kendaraan & Sepeda: $\operatorname{Rp} 30.000 /$ jam \\
\hline & & Motor listrik: $\mathrm{Rp}$ \\
\hline & & $5.000 /$ jam \\
\hline & & Kereta kuda: Rp \\
\hline & & $25.000 /$ jam \\
\hline & & Mobil wisata: $\mathrm{Rp}$ \\
\hline & & $\begin{array}{l}20.000 \text { (dewasa) dan Rp } 10.000 \text { (anak) Bus Wisata: Rp. } \\
500.000 \text { (40 orang) }\end{array}$ \\
\hline 6.MP4 & $\begin{array}{l}\text { Wisata Kuliner - Tempat } \\
\text { Pernakpernik }\end{array}$ & $\begin{array}{l}\text { Jarak tempuh dari wisata kuliner ke tempat pernak } \\
\text { pernik tersebut adalah } 15 \text { meter }\end{array}$ \\
\hline 7.MP4 & Pernak-pernik - bom bom mobil & $\begin{array}{l}\text { Tempat pernakpernik untuk naik mobil bom bom } 80 \\
\text { meter }\end{array}$ \\
\hline 8.MP4 & Bom-bom car - SkyTower & $\begin{array}{l}\text { Bom mobil yang } \\
\text { tidak lagi beroperasi dan menara langit dalam tahap } \\
\text { perbaikan }\end{array}$ \\
\hline 9.MP4 & Sky Tower - Patung naga & Jarak Sky Tower ke patung naga adalah 210 meter \\
\hline 10.MP4 & $\begin{array}{l}\text { Pelabuhan pulau - Rumah lamin } \\
\text { adat }\end{array}$ & $\begin{array}{l}\text { Dari dermaga tersebut, penyeberangan } \\
\text { menuju rumah lamin tradisional berjarak } 390 \text { meter }\end{array}$ \\
\hline 11.MP4 & $\begin{array}{l}\text { Rumah lamin adat - patung } \\
\text { Lembuswana }\end{array}$ & $\begin{array}{l}\text { Laminasi khusus } \\
\text { (pusat pengalaman } \\
\text { Dayak) } \\
\text { Pasak Pura } \\
\text { Lamin adat (tempat pertunjukan) Wisata adat lamin } \\
\text { Patung Lembuswana }\end{array}$ \\
\hline
\end{tabular}

\subsection{Video Editing}

Pengeditan video adalah proses aktivitas untuk membuat video lebih teratur dan menyenangkan oleh pengguna. Ada banyak bagian yang termasuk video editing yaitu cropping gambar, resize, pengaturan suara video, penambahan judul dan transisi.

Pemotongan gambar dilakukan dengan menggunakan tol, yang fungsinya untuk menghapus gambar yang tidak perlu. Pengaturan ukuran digunakan untuk mengatur ukuran gambar besar atau kecil ukuran yang diinginkan. Menambahkan judul dapat digunakan untuk membuat kredit atau judul video. Transisi digunakan untuk membuat klip video lebih baik dan lebih nyaman dilihat oleh penonton. Berikut adalah contoh yang menampilkan video editing pada aplikasi Premiere Pro. 
doi: 10.47002/metik.v5i1.201

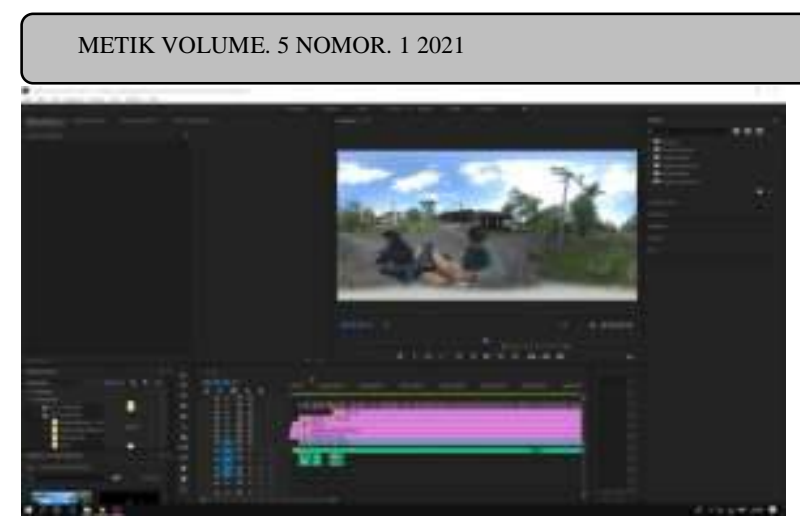

Gambar 3. Membuat Sequence dengan cepat

\subsection{Pengembangan aplikasi}

Membuat aplikasi Virtual reality yang harus kita lakukan pertama kali adalah membuat project baru dan menentukan lokasi penyimpanannya, kemudian klik Create Project untuk melanjutkan. Impor semua aset yang digunakan untuk membuat aplikasi Virtual Reality, misalnya seperti semua video, aset luar dalam, Google VR untuk Unity dan foto yang berguna untuk membuat VR.

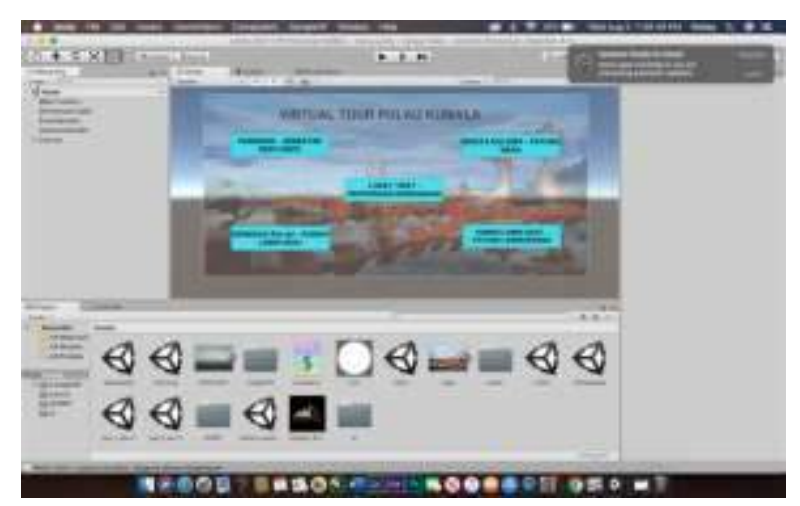

Gambar 4. Proses penambahan asset

\subsection{Test Perangkat}

Aplikasi yang telah berhasil dikembangkan ini kemudian diujicobakan pada beberapa smartphone untuk melihat apakah aplikasi tersebut dapat diinstal dan berjalan dengan baik serta berjalan dengan baik pada versi Android. Pengujian perangkat dilakukan secara manual dengan menginstal setiap perangkat yang ada. Berikut hasil pengujian yang dilakukan pada beberapa smartphone.
Tabel 3. Testing Devices

\begin{tabular}{|c|c|c|c|c|}
\hline $\begin{array}{l}\text { Nama } \\
\text { perangkat }\end{array}$ & $\begin{array}{l}\text { Android } \\
\text { Version }\end{array}$ & $\begin{array}{l}\text { Resolusi } \\
\text { layar }\end{array}$ & Gyroscope & Continuity \\
\hline Mi A1 & $\begin{array}{c}7.0 \\
\text { Nougat }\end{array}$ & $\begin{array}{l}1920 x \\
1080 \\
(16: 9)\end{array}$ & Bisa & Lancar \\
\hline $\begin{array}{l}\text { Redmi } \\
\text { Note } 5\end{array}$ & 8.0 Oreo & $\begin{array}{l}1080 x \\
2160 \\
(18: 9)\end{array}$ & Bisa & Lancar \\
\hline $\begin{array}{l}\text { Redmi } 6 \\
\text { pro }\end{array}$ & 8.1 Oreo & $\begin{array}{l}2280 x \\
1080\end{array}$ & Bisa & Lancar \\
\hline
\end{tabular}

Pengujian sejumlah set aplikasi ini berjalan dengan baik dan tidak ada kendala sama sekali. Mulai dari resolusi layar dengan resolusi 16: 9, 18: 9 dan 19: 9, aplikasi ini mampu berjalan dengan indikasi giroskop berjalan dengan lancar dan aplikasi juga tidak force close. Akan tetapi, aplikasi ini tidak dapat dijalankan dengan versi android di bawah ini dimulai dari versi Android KitKat (4.4) karena APi yang digunakan tidak mendukungnya. Uji coba yang dilakukan pada Redmi 6 Pro dapat dilihat berikut ini.

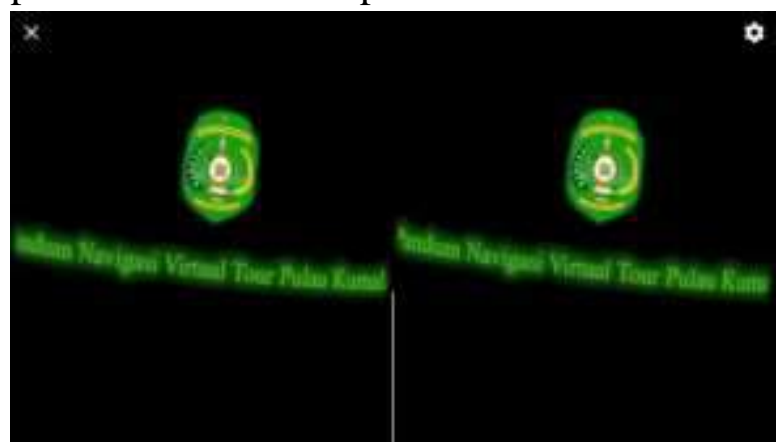

Gambar 5. Tampilan pada gawai

\subsection{Distribution}

Aplikasi yang telah diuji dan dinyatakan baik sesuai dengan tujuan pembuatannya akan didistribusikan dengan cara mengunggah akun youtube Dinas Pariwisata Kabupaten Kutai Kartanegara. Berikut tahapan pendistribusiannya:

\section{Upload Video Di Youtube}

Sebelum unggah video ke YouTube, langkah pertama yang harus dilakukan adalahmenambahkan metadata video yang akan kita upload ke YouTube sehingga memiliki tampilan 360 derajat dan dilengkapi fitur kacamata Viritual Reality. Setelah penambahan metadata selesai, kamu bisa 
langsung menguploadnya di channel youtube yang sudah dibuat sebelumnya dengan menggunakan akun google.

Buka YouTube dan gambar Anda memiliki akun YouTube untuk unggah video yang akan dibagikan, tekan ikon video plus opsi, opsi pencarian, tambahkan judul, deskripsi video dan atur thumbnail.

\section{Distribusi Aplikasi}

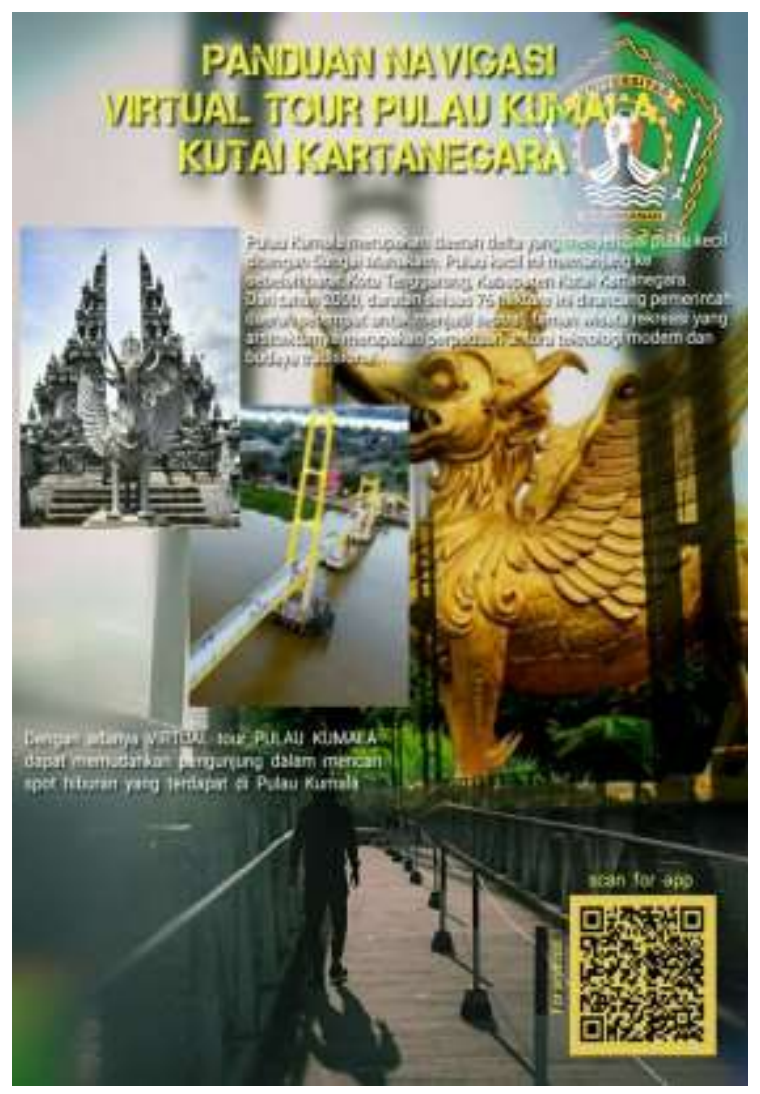

Gambar 6. e-Poster

Distribusi aplikasi dilakukan setelah semua proses dalam proses pembuatan telah selesai. Pembagian dilakukan agar videovideo yang telah dibentuk sedemikian rupa dapat dinikmati oleh seluruh masyarakat dan diharapkan dapat menambah ilmu pengetahuan dan lebih tertarik untuk mengunjungi Pulau Kumala Tenggarong. Adapun pendistribusian aplikasinya secara online adalah dengan menggunakan menggunakan E-poster.

\section{Kesimpulan}

Berdasarkan hasil dan pembahasan yang telah diuraikan pada bab sebelumnya maka dapat dihilangkan sebagai berikut. Aplikasi
Panduan Navigasi VR Pulau Kumala Kutai Kartanegara Virtual Tour yang dibangun mampu memvisualisasikan objek seperti wahana, jarak, biaya dan tempat yang ada di Pulau Kumala Tenggarong.

Berdasarkan pengujian perangkat, aplikasi dapat berjalan dengan lancar di perangkat android dengan versi android 7.0 (nougat) hingga android versi 8.1 (oreo). Panduan Navigasi Tur Virtual Pulau Kumala juga dapat digunakan di media sosial YouTube dan dapat diakses dengan tampilan video 360 derajat atau tampilan CardBoard untuk kacamata VR. Hasil pengujian berdasarkan aplikasi angket yang menunjukkan bahwa setiap pertanyaan dari angket memperoleh jawaban setuju dan sangat setuju yang menandakan respon positif dari pengguna aplikasi.

\section{Daftar Pustaka}

[1] A. Tejawati, M. B. Saputra, M. B. Firdaus, S. Fadli, F. Suandi, and M. K. Anam, "Media Promosi Penangkaran Rusa Sambar (Rusa Unicolor) Sebagai Ekowisata Di Penajam Paser Utara Berbasis Virtual Reality," J. Inform. dan Rekayasa Elektron., vol. 2, no. 2, p. 52, 2019, doi: 10.36595/jire.v2i2.118.

[2] M. B. Firdaus, E. Budiman, Haviluddin, M. Wati, H. J. Setyadi, and H. S. Pakpahan, "An openness of government website content using text analysis method," Int. J. Eng. Adv. Technol., vol. 8, no. 5, pp. 1461-1466, 2019, doi: 10.35940/ijeat.E1214.0585C19.

[3] M. B. Firdaus, E. Budiman, joan angelina Widians, novel maringan Sinaga, S. Fadli, and F. Alameka, "Augmented Reality for Office and Basic Programming Laboratory Peripheral," 2018 2nd East Indones. Conf. Comput. Inf. Technol., vol. 2, no. 2, pp. 41-45, 2018.

[4] B. Cahyono, M. B. Firdaus, E. Budiman, and M. Wati, "Augmented Reality Applied to Geometry Education," 2018 2nd East Indones. Conf. Comput. Inf. Technol., vol. 2, no. 
2, pp. 299-303, 2018.

[5] N. Dengen, H. S. Pakpahan, G. F. Putra, M. B. Firdaus, R. Wardhana, and A. Tejawati, "An Augmented Reality Model Physical Transformation Learning," ICEEIE 2019 - Int. Conf. Electr. Electron. Inf. Eng. Emerg. Innov. Technol. Sustain. Futur., pp. 255-259, 2019, doi: 10.1109/ICEEIE47180.2019.8981444

[6] C. Fenu and F. Pittarello, "Svevo tour: The design and the experimentation of an augmented reality application for engaging visitors of a literary museum," Int. J. Hum. Comput. Stud., vol. 114, pp. 20-35, 2018, doi: 10.1016/j.ijhcs.2018.01.009.

[7] M. Budwig, "When User Experience Met Agile : A Case Study,” Chi 2009, $\mathrm{pp}$

3075-3083,

2009, doi:

$10.1145 / 1520340.1520434$

[8] P. K. Tsung, P. C. Lin, L. F. Ding, S. Y. Chien, and L. G. Chen, "Single iteration view interpolation for multiview video applications," $3 D T V$ CON 2009 - 3rd 3DTV-Conference True Vis. - Capture, Transm. Disp. 3D Video, Proc., pp. 3-6, 2009, doi: 10.1109/3DTV.2009.5069621.

[9] J. Fang, Z. Zhao, C. Wen, and R. Wang, "Design and performance attributes driving mobile travel application engagement," Int. J. Inf. Manage., vol. 37, no. 4, pp. 269-283, 2017 , doi: 10.1016/j.ijinfomgt.2017.03.003. 